\title{
Coexisting Gout and Chondrocalcinosis on Hand Radiograph
}

FABRICE COUTIER; MAXIME SONDAG, MD; DANIEL WENDLING, MD, PhD, Department of Rheumatology, University Teaching Hospital, Besançon, France. Address correspondence to Dr. F. Coutier, Department of Rheumatology, University Teaching Hospital, 3 Blvd. Alexandre Fleming, 25030 Besançon, France. E-mail: fabrice.coutier@edu.univ-fcomte.fr. Ethics approval for this case report was not required in accordance with the policy of the authors' institution. J Rheumatol 2018;45:723-4; doi:10.3899/jrheum.171154

Gout and chondrocalcinosis are frequent crystal arthropathies, but they rarely coexist in the same joint. Radiographs can highlight specific signs of these 2 diseases.

A 95-year-old woman with a history of hypertension, type 2 diabetes mellitus, and gout was admitted to the rheumatology department for sudden-onset foot pain. She had no fever and physical examination revealed erythema, tenderness, and swelling of the first right metatarsophalangeal joint. There were also multiple tophi of the hands. Blood tests showed elevated levels of uric acid $(10.8 \mathrm{mg} / \mathrm{dl})$ and C-reactive protein $(2.91 \mathrm{mg} / \mathrm{dl})$, and secondary hyperparathyroidism with vitamin $\mathrm{D}$ deficiency [ionized calcium level $1.25 \mathrm{mmol} / \mathrm{l}$, phosphate level $0.70 \mathrm{mmol} / \mathrm{l}$, parathyroid hormone (1-84) level $195 \mathrm{pg} / \mathrm{ml}, 25$-hydroxy vitamin D level $7 \mathrm{ng} / \mathrm{ml}$. Kidney function was unremarkable. Anticyclic citrullinated peptide antibodies were negative. Radiographic examination of the hands showed typical chondrocalcinosis: calcifications in the carpal triangular fibrocartilages, in the trapeziometacarpal joints, and surrounding several metacarpophalangeal joints of both hands. Hand radiograph also showed multiple large eccentric periarticular erosions ("punched out" erosions), especially of the proximal extremity of the phalanx of the second left proximal interphalangeal joint, associated with swelling and hyperdensity of surrounding soft tissue, suggesting gout arthropathy (Figure 1 and Figure 2).

Coexistence of gout and chondrocalcinosis (also known as pseudogout) has been previously reported: a study of 138 gout patients showed that 8 of them had chondrocalcinosis of the knees, and 6 of those 8 patients had chondrocalcinosis elsewhere ${ }^{1}$. The association of gout and chondrocalcinosis in the same joint has also been described ${ }^{2}$. The particularity of this case is the coexistence of gout and chondrocalcinosis in the same joints and in both hands.

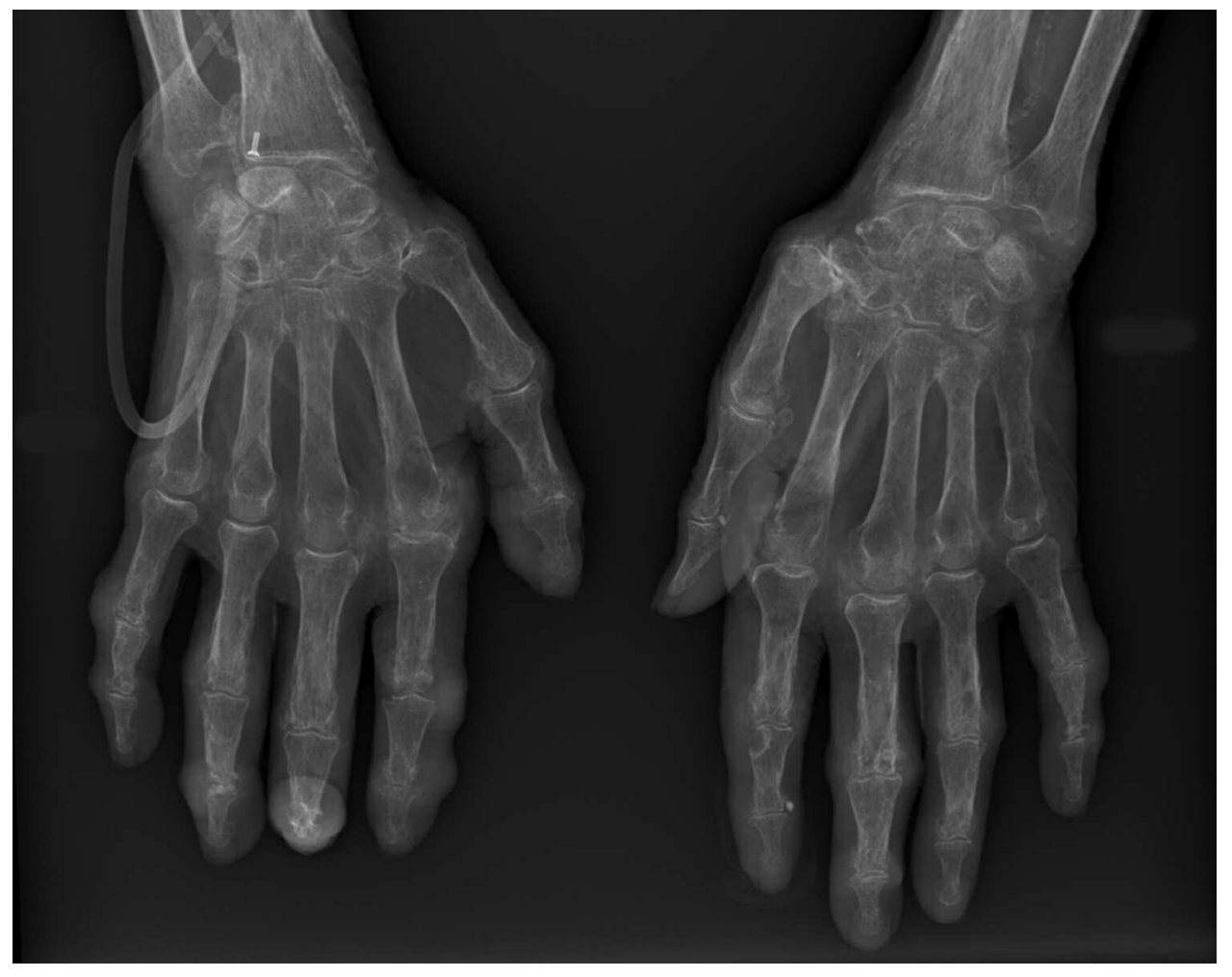

Figure 1. AP radiograph of the hands reveals tophi and erosions of both distal and proximal interphalangeal joints, and chondrocalcinosis in the metacarpophalangeal joints and triangular fibrocartilage. AP: anteroposterior.

Personal non-commercial use only. The Journal of Rheumatology Copyright (c) 2018. All rights reserved. 


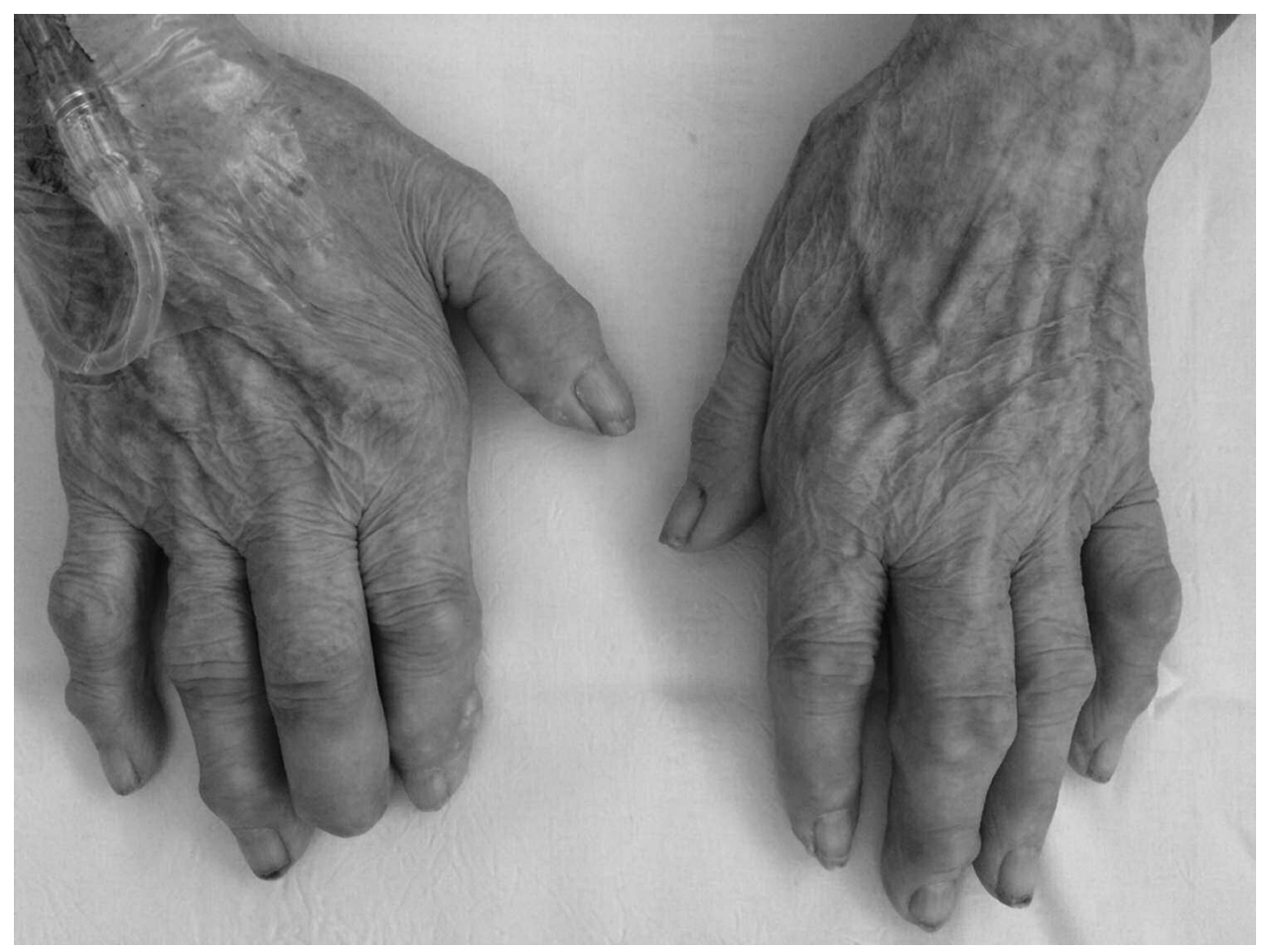

Figure 2. Multiple tophi of the hands.

\section{REFERENCES}

1. Stockman A, Darlington LG, Scott JT. Frequency of chondrocalcinosis of the knees and avascular necrosis of the femoral heads in gout: a controlled study. Ann Rheum Dis 1980;39:7-11.
2. Yoo Y, Seo YJ, Huh M, Yoo JH, Yun KH, Kim SJ. Gout and coexisting pseudogout in the knee joint. Knee Surg Sports Traumatol Arthrosc 2011;19:553-5. 